\title{
BOYS' BMI FROM EARLY PRESCHOOL TO LATE ADOLESCENCE: EVALUATION OF SIX DECADES' DATA
}

\author{
Gábor A. Tóth ${ }^{1}$, Csilla Suskovics ${ }^{2}$, Botond L. Buda ${ }^{3}$, \\ Germaine CoRnÉLISSEN ${ }^{4}$ \\ ${ }^{1}$ University of West Hungary, Savaria Campus, Institute of Biology, \\ Szombathely, Hungary \\ ${ }^{2}$ University of West Hungary, Savaria Campus, Institute of Sport Science, \\ Szombathely, Hungary \\ ${ }^{3}$ Private Practice for Neurosomnology, Szombathely, Hungary \\ ${ }^{4}$ Halberg Chronobiology Center, University of Minnesota, Minneapolis, USA
}

\begin{abstract}
Growth and maturation of children is a dynamic and complex biological process, influenced by both genetic and environmental factors. Children's growth pattern can change from time to time, therefore, it is necessary to investigate the state of children's somatic development repeatedly. According to a widely accepted and scientifically proven theory, the children's growth and maturation status is a sensible indicator of the nutritional and health conditions of the general population. Thus, the information about the growth and the development of children and youth mirrors the biological status and/or welfare of a population. The "Körmend Growth Study", a chain of repeated cross-sectional growth studies performed on children in the town of Körmend (Hungary) was one of the first realizations of this principle. Anthropological investigations have been performed in Körmend in every 10 years since 1958 in a systematic way. The data are prepared from groups of 1,563 to 2,867 boys in Körmend, between 1958 and 2008 at 10-year intervals. The Body Mass Index (BMI) was introduced into the human biology practice for the statistical evaluation of the nutritional status according to the suggestions of Keys and coworkers. Comparing distinct ten-year intervals from 1958 to 2008, a characteristic tendency of the BMI can be observed in boys.
\end{abstract}

Keywords: Body Mass Index: Körmend Growth Study 


\section{INTRODUCTION}

Growth and maturation of children is a dynamic and complex biological process, influenced by both genetic and environmental factors. Children's growth pattern can change from time to time, therefore, it is necessary to investigate the state of children's somatic development repeatedly. According to a widely accepted and scientifically proven theory, children's growth and maturation status is a sensible indicator of the nutritional and health conditions of the general population. Thus, the information about the growth and the development of children and youth mirrors the biological status and/or welfare of a population.

Describing the build-up of the human body by informative body measures as precisely as possible is an ancient endeavour of human biology and medicine, respectively. The simplest methods used in practice are based on evaluating the body mass to the body height ratio. From the $19^{\text {th }}$ century on, indices and methods underwent certain evolutional changes, from the Quetelet's method through the Rohrer's and the Kaup's modifications till the Body Mass Index (BMI, $\mathrm{kg} / \mathrm{m}^{2}$ ), suggested by the American Keys et al. [among others: 3, $5,1]$. The BMI is widely used for evaluating the nutritional status and determining the degree of "fattiness" as well. Knowing the BMI, tracing the changes of malnutrition, overnutrition and obesity is essential. The qualitative and quantitative consistence of nutrition is particularly important in childhood, especially during the rapid growth periods. However, empirical data suggest that the method is not suitable for assessing the body composition [3], because no distinction is made either on the basis of the certain body compounds or based on different width and circumferential body measures.

\section{MATERIAL AND METHODS}

The investigation has been conducted in Körmend. Körmend is a small town in West Hungary, Central Europe. The KGS was set up by professor Eiben. Dr. Ottó Eiben (1931-2004) was professor and chair at the Department of Anthropology at Eötvös Loránd University, and, after his retirement, a fellow at the Churchill College in Cambridge. The principal field of his scientific research activity was the growth and maturation of children and the secular trend. His favourite work was undoubtedly the Körmend Growth Study (KGS). It is widely known that the KGS proved in Hungary the tendencies observable during the growth and maturation of children to be partial manifestations of the so-called secular trend. The KGS was started in 1958 (K-58) by Ottó Eiben, 
and thereafter he repeated his investigations in every ten years - K-58, K-68, K-78, K-88. In 1998 the study was carried out by Eiben and Tóth - K-98, and after Eiben's death KGS - K-008 was organized by Tóth [3, 4, 9].

The aim of the study was to involve all healthy 3-18-year-old boys and girls living in the town, i.e. all preschoolers and school children. The representation has usually been well over $95 \%$, except in the case of K-98 (76\%), and in the case of K-008 (72\%). Decimal age of the subjects was calculated.

The anthropometric program of the KGS was very extensive. Fifteen body measures and 10 head and face measures were taken in 1958 (K-58). In K-68 21 body measures were taken, and during K-78, K-88, K-98 and K-008, on the basis of the same principle, 23 body measures formed the anthropometric programme.

Methods and techniques of the investigations were in accordance with the internationally accepted standards described by Martin and Saller [6]. The recommendations of the International Biological Programme, Human Adaptability section, were also taken into consideration [8]. The authors are experienced in applying these methods. Traditional mathematical-statistical parameters were calculated. In the last studies, modern computers, the BMDP and the SPSS statistical softwares were used.

Professor Eiben has published several papers about the KGS. He has summarized the results of the first three-four investigations in a small monograph [2] containing a complete list of papers published about the KGS till then. Fifteen years later he published another monograph about the ongoing KGS [3]. In this monograph he described all economic and social changes Körmend children's lifestyle and somatic development was influenced by. He pointed out that the population's relative genetic balance had somewhat changed, especially as an effect of the accelerated migration from the last decade of the $20^{\text {th }}$ century on. The healthcare system, nutritional conditions and community sustenance have been improved remarkably. Schools and flats have been modernized; interpersonal relations have improved, too. Physical activity of boys and girls has changed as well. A slight shift in social stratification could also be observed. The population's relative genetic balance has somewhat changed, especially as an effect of migration in the last two decades. Over this half-a-century period of time, the small settlement developed from an agricultural village into a moderately industrialized town. Its population increased, and its infrastructure improved remarkably. 


\section{RESULTS AND DISCUSSION}

Data were gained from a table of the Körmend Growth Study results, obtained from the groups of 1,563 to 2,867 boys in Körmend, Hungary between 1958 and 2008 at 10 -year intervals. The average BMI values for boys in each age group were plotted as a function of age for each cohort.

Visual inspection of Figure 1 indicates that the BMI starts increasing around 6 years of age and that the increase was highest in the last cohort.

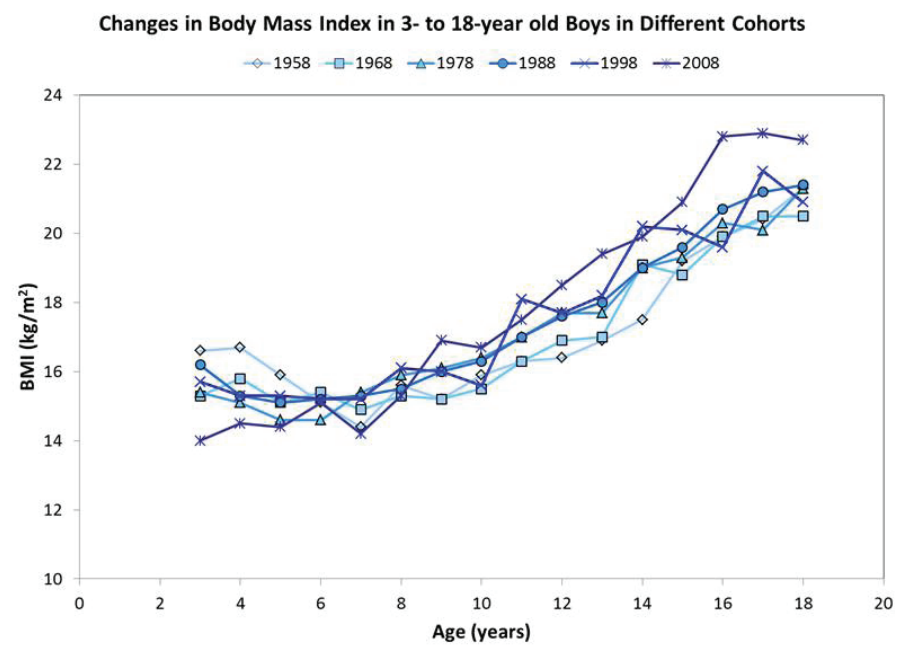

Figure 1. Changes in Body Mass Index in 3-18-year-old boys in different cohorts.

The table also reported the standard deviation (SD), associated with each average BMI value, as a measure of the spread of the distribution. Regarding the increase in the BMI as a function of age, it can be expected that the corresponding SD will also increase as a function of age. This is indeed the case, as shown for each cohort (series) in Figure 2, notably in the case of the last cohort studied in 2008. Averaging across the six cohorts (Figure 3), the increase in the BMI-SD is statistically significant by 1 -way analysis of variance (ANOVA) $(\mathrm{F}=2.347, \mathrm{P}=0.008)$. 


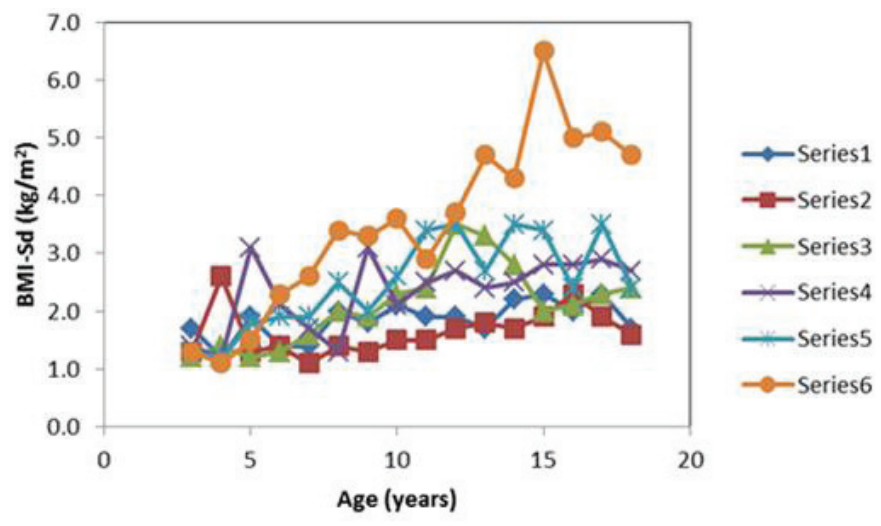

Figure 2. BMI-SD and the cohorts.

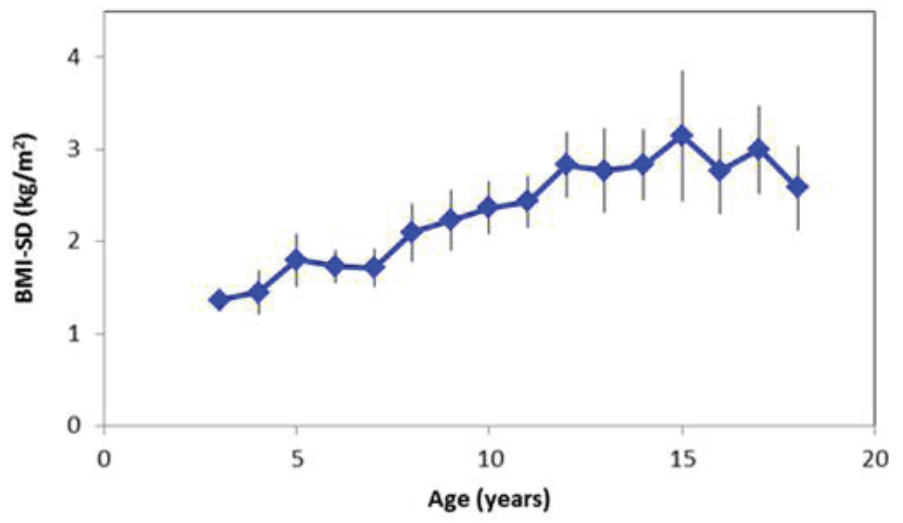

Figure 3. Averaging across the six cohorts.

Not only is there an increase in the BMI-SD as a function of age, the width of the BMI distribution also increases as a function of time, being larger in the latest cohorts, Figure 4. The fit of a linear trend indicates that the increase is statistically significant (dashed line in Figure 4). 


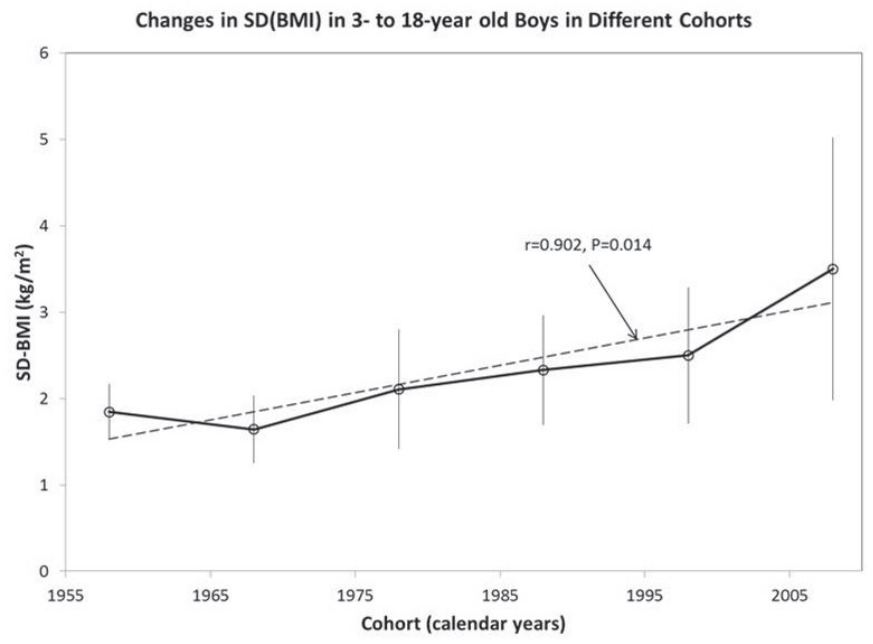

Figure 4. Changes in SD (BMI) in 3-18-year-old boys in different cohorts.

In order to examine whether there may be any pattern other than an increasing trend in the BMI, the BMI values in cohorts $2-6$ were expressed as a percentage of the BMI value in 1958 (cohort 1). In other words, the BMI value in 1958 was set to $100 \%$ for all age groups and the corresponding BMI values in later cohorts of a given age were expressed as a percentage of that $1958 \mathrm{BMI}$ value in the same age group. The increase in the width of the BMI distribution is readily apparent from Figure 5, with the qualification that the trend may be opposite for some age groups, Figure 6 (these are the younger age groups, not shown in Figure 6).

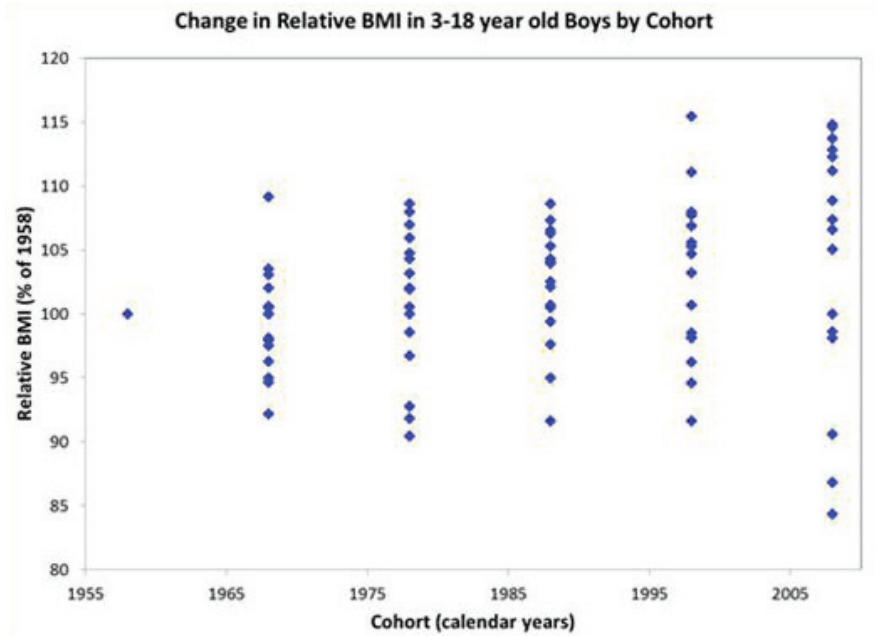

Figure 5. Change in relative BMI in 3-18-year-old boys by cohort. 


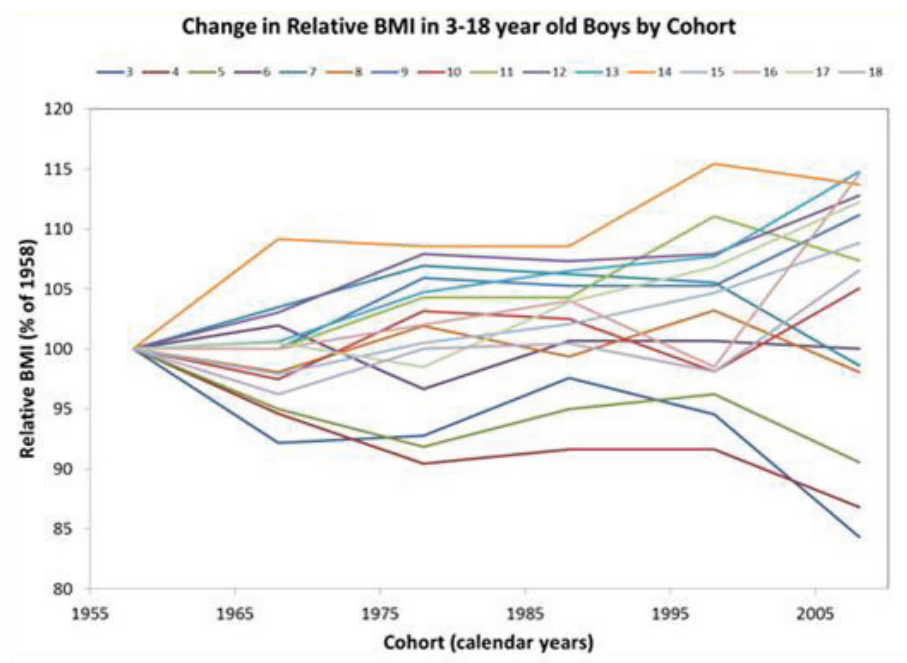

Figure 6. Change in relative BMI in 3-18-year-old boys by cohort.

Averaging the relative BMI values across all age groups (the trend as a function of age has been eliminated by the normalization procedure), a linear increase as a function of time can be observed, the latest cohort having a relative BMI value $4.1 \%$ higher than the 1958 cohort. As shown in Figure 7, the trend is statistically significant.

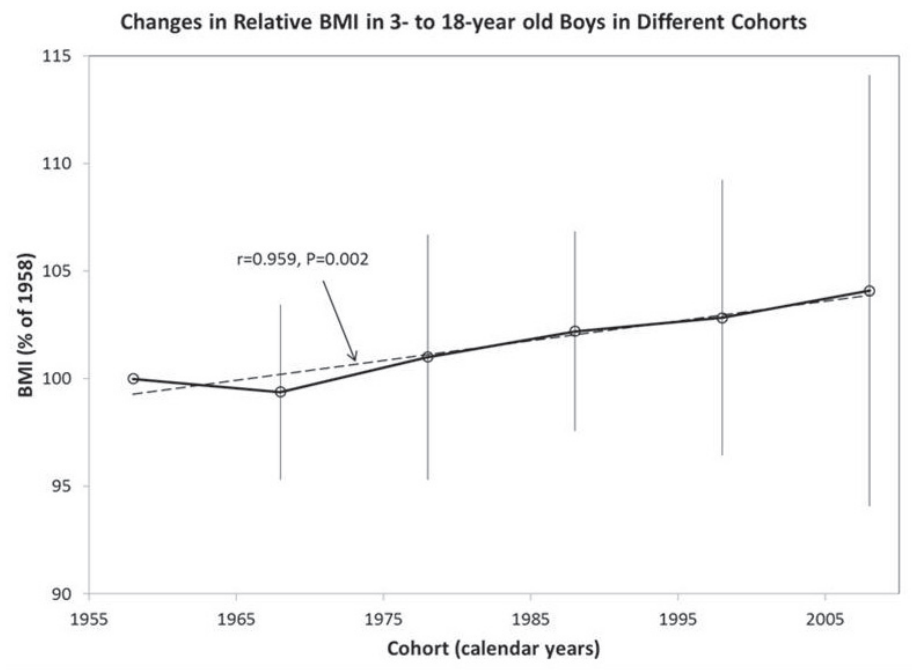

Figure 7. Changes in relative BMI in 3-18-year-old old boys in different cohorts. 
In order to examine whether the decrease in the BMI seen early in life, preceding the increase observed after 7 years of age, is statistically significant, the actual BMI values were fitted with a third-order polynomial, Figure 8. Overall, the model is highly statistically significant $(\mathrm{R} 2=0.907, \mathrm{P}<<0.001)$, each term contributing with statistical significance as well $(\mathrm{P}<0.001)$. For an assessment of the ages at which extrema are reached, the first-order derivative of the third-order polynomial was computed and equated to zero, and the resulting second-order equation solved for age. The age at which the minimum is reached is estimated at 4.5 years and the age at which the maximum is reached (corresponding to the plateau observed in Figure 8 ) is estimated at 22.4 years. The year of the minimal BMI found in this study is similar to that published by Salti et al. [7].

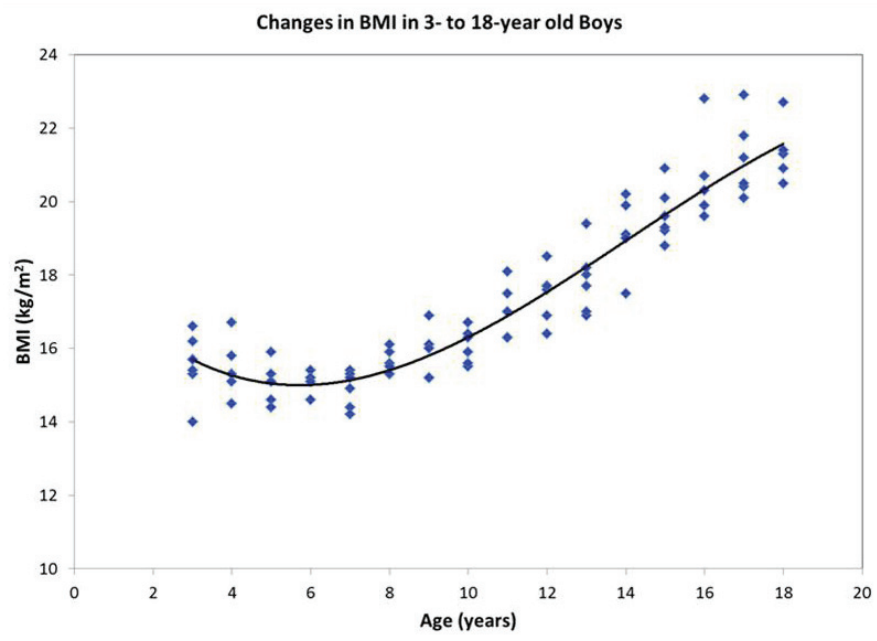

Figure 8. Changes in BMI in 3-18-year-old boys.

\section{CONCLUSIONS}

The Body Mass Index (BMI) was introduced into the human biology practice for the statistical evaluation of the nutritional status according to the suggestions of Keys and coworkers. Comparing distinct ten-year intervals from 1958 to 2008, a characteristic tendency of the BMI can be observed in boys. Comparing distinct ten-year intervals from 1958 to 2008, a decreasing tendency of the BMI can be observed in boys until the age of 8 . However, beginning from the age of 9 , these values begin to increase rapidly. This increasing process tends to get more dynamical from the age of 13 , which corresponds to 
the greater fat deposition in the hip and abdominal region at that age, especially in the epoch of K-008. That should draw our attention to the likelihood of later adulthood abdominal type obesity as a risk factor. Comparing the statistical parameters of the Body Mass Index of boys, respectively, calculated in 2008 (K-008), stagnancy under the value of $15 \mathrm{~kg} / \mathrm{m}^{2}$ (or incidentally slightly exceeding it) can be stated in both genders until the age of 8 . From the age of 9 on, increasing can be observed.

\section{REFERENCES}

1. Claessens A.L., Beunen G., Malina R.M. (2008). Anthropometry, physique, body composition and maturity. In: Armstrong N., Van Mechelen W. (Eds.), Paediatric Exercise Science and Medicine. Oxford: Oxford University Press, 23-26.

2. Eiben O.G. (1988). Secular Growth Changes in Hungary. Humanbiol. Bud., Suppl. 6. Budapest.

3. Eiben O.G. (2003). Biological Developmental Status of the Körmend Youth in the Second Half of $20^{\text {th }}$ Century. Kärmend: Körmendi Füz.

4. Eiben O.G., Tóth G. (2000). Half-a-century of the "Körmend Growth Study". Coll. Antropol., 24, 431-441.

5. Eiben O.G., Tóth G.A., Van Wieringen J.C. (2007). Weight/height indices in Hungarian youth during the Twentieth Century. In: Singh S.P., Gaur R. (Eds.), Human Body Composition. Delhi: Kamla-Raj Enterpris, 9-16.

6. Martin R., Saller K. (1957). Lehrbuch der Anthropologie, I. Stuttgart: Gustav Fischer.

7. Salti R., Stagi S., Galluzzi F. (2004). Overweight and obesity. In: Nicoletti I., Benso L., Gilli G. (Eds.), Physiological and Pathological Auxology. Firenze: Edizioni Centro Studi Auxologici, 445-463.

8. Tanner J.M., Hiernaux J., Jarman S. (1969). Growth and physique studies. In: Weiner J.S., Lourie J.A. (Eds.), Human Biology. A Guide to Field Methods. IBP Handbook, 9. Oxford, Edinburgh: Blackwell Sci. Publ., 1-76.

9. Tóth G.A., Buda B.L., Suskovics Cs. (2015). A classical secular trend research from Central Europe: The Körmend Growth Study. In: Sikdar M. (Ed.), Human Growth. The Mirror of the Society. Delhi: B. R. Publisher Corporation, 169-199.

\section{Adress for correspondence}

Dr. habil. Gábor A. Tóth

University of West Hungary, Savaria Campus, Institute of Biology

Károlyi G. tér 4. 9700 Szombathely, Hungary

e-mail: gabor.toth@nyme.hu 